\title{
Ocean Sciences During the Fall Season: The End and the Beginning
}

For those who live in the higher latitudes of the Northern Hemisphere, the fall season usually marks the end of summer fieldwork. This year, for some of us, the field season never fully started or didn't happen at all, as the coronavirus pandemic changed the world. Many oceanographers were unable to venture out to sea, take samples, and observe and record environmental conditions. We could not proudly look back on a new discovery or an exciting data set that should prove our hypothesis or provide new insights into an ocean process. We could not deploy a new set of autonomous instruments to collect continuous observations and celebrate its success. In a pre-pandemic world, we would now be looking forward to working up field data in our offices and laboratories and repairing and refurbishing instruments. Maybe we would also be catching our breath and reflecting on the season.

The pandemic has noticeably impacted many other aspects of our work. During late spring, access to laboratories was significantly restricted, and our intricate plans for the summer field season were falling apart. New plans needed to be made quickly and were obsolete again a short time later. We needed to be flexible and were constantly adjusting the way we perform our science. We felt exhausted before the field season began, not knowing if, in fact, it even would begin. Instantly, most of our communications were switched to digital media. There was no sharing of a coffee, no bumping into a colleague randomly, no chitchats with students and staff. Hope for a quick return to "normal" gave way to the realization that the global pandemic will be with us for many months to come.

Today, we are still weary. The field season was barely productive. We participate in a seemingly endless stream of online meetings. We are tired of staring at the computer screen and long for those days in the field and when we could meet in person with colleagues. Although we move less physically, the rapid switching from online meeting to online meeting leaves us breathless and exhausted. We simply need a break from it all.

On the other hand, the fall season also marks a beginning. It is typically when many expert gatherings happen where we share our discoveries and discuss and debate our science with colleagues. It is also the time to publish and teach. Moreover, it is a time to begin planning for the next field season and assemble new teams, establish new partnerships, and sketch out a new project or experimental setup. The anticipation of the next summer's field season with better sensors or more instruments, a new ship or platform, or a more promising location keeps us optimistic.
Fall is also a good time to consider our plans for ocean sciences in the coming years and post-pandemic times. As a result of the pandemic, TOS learned how to run electronic meetings efficiently. We've had more TOS Council meetings than in past years, with much greater attendance. We miss the social interactions, but our meetings are now shorter, with stringent agendas, and the frequent use of electronic voting tools helps to rapidly come to consensus. There seems little desire to go back to in-person Council meetings.

What have we accomplished at TOS? We have established three new awards-TOS Mentoring, TOS Early Career, and TOS Ocean Observing-and have grown our student membership dramatically. We have also used this year to reflect generally on the ocean science community engaged in TOS. Have we succeeded in connecting to and fully embracing new opportunities? As a first step in reaching out further, the TOS Council established three new Council positions: one to bring in the perspective of the early career scientist, one to engage deeper with the ocean data and informatics community, and one to enhance connections with the areas of social science, ocean policy, and ocean governance. We also considered the broad profile of our TOS membership and the ocean sciences community and determined that TOS does not fully reflect the diversity of the greater society. We established a JEDI committee that is charged with making concrete suggestions to advance issues of justice, equity, diversity, and inclusion. The committee will support the TOS community in embracing and celebrating our differences, broadening participation, and creating a culture of belonging. Moreover, we are engaging in deep discussions about the future of our Ocean Sciences Meetings, with the next one scheduled for 2022 in Hawai i $i$. What is the optimal mix of in-person and remote participation? How will the business model shift? How can we best support our TOS and ocean sciences communities?

Looking back over 2020, we mourn a partially missed field season, personal hardships, and significant disruptions. At The Oceanography Society, we have only partially completed our TOS 2030 Strategy process. But once the winter season wanes, we expect that all of us will feel energized and ready for a new ocean science season. We look forward to deeply engaging with our membership to develop an exciting, innovative, impactful, and inclusive TOS Strategy 2030 in order to shape the future of our Society.

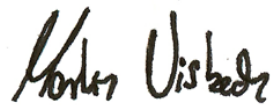

Martin Visbeck, TOS President 